\title{
Participatory plant breeding: the best way to breed for sustainable agriculture?
}

\author{
Y. Chiffoleau ${ }^{1 *}$ and D. Desclaux ${ }^{2}$ \\ ${ }^{1}$ INRA UMR Innovation, Montpellier, France; and ${ }^{2}$ INRA UMR Diversité et Génome des Plantes Cultivées, \\ Domaine de Melgueil, Manguio, France
}

\begin{abstract}
Participatory plant breeding began in developing countries and now some European farmers and scientists are proposing its suitability in contributing to sustainable agriculture. This paper uses both genetics and sociology to determine the conditions required. A review of the sustainability of projects implemented in developing countries initiated discussion of an organic durum wheat participatory breeding programme, which is currently being implemented in the south of France. The analysis highlighted the need for the critical participation of experts from different horizons in a socio-technical network. Multi-level interactions and cross-linked learning processes about breeding methods and sociological concepts are needed for effective communication between different stakeholders and scientific disciplines. This approach enables implementation of a range of different action systems in which the production of relevant knowledge and rules addresses the issue of the sustainable development of diverse agro-food systems, rather than the generalization of one model.
\end{abstract}

Keywords: Organic durum wheat production, participatory plant breeding, multidisciplinary approach, socio-technical network, sustainable agriculture

\section{Introduction}

Participatory plant breeding (PPB) projects have been initiated by international research institutes to increase the adoption of cultivars by small farmers in developing countries (Almekinders \& Elings, 2001). More recently, PPB has appeared in European countries in the form of socio-political and scientific projects. These have been implemented by farmers' associations to promote sustainable agriculture and by researchers preoccupied with the conservation of biodiversity. These actors refer to the results of PPB programmes implemented in developing countries to justify the 'transfer' of such initiatives to Europe. However, given the enormous diversity of PPB programmes, the ideal conditions and modalities needed to ensure PPB guarantees

*Corresponding author. Email: chiffole@ensam.inra.fr sustainable agriculture in European countries need to be analysed. This paper carries out this analysis and uses an approach which combines genetics and sociology.

Beyond the disciplinary issues raised by sustainable agriculture, lies the challenge of expressing concepts related to biotechnical and social sciences in a pragmatic way, which is accessible to different stakeholders. Sustainable agriculture is a new paradigm that refers to a whole range of innovative farming practices which can be evaluated from different and intersecting points of view, such as environmental impacts, social issues and economic profitability (Godard \& Hubert, 2002). Researchers, farmers, policy-makers and economists are confronted with a cognitive challenge which routine knowledge cannot overcome. Management studies interpret sustainable agriculture as a problem of conception for both researchers and 
stakeholders caught in a new 'socio-economic order' (Aggeri \& Hatchuel, 2003). Collective action is presented as the precondition for crosslinked learning processes, and participatory methods are proposed to facilitate the production of knowledge that is relevant to the challenge of ensuring sustainability. PPB programmes thus appear as enlightening action-research tools, that enhance understanding of the issues linked with both collective action and stakeholders' participation in agricultural research programmes, that are aimed at sustainability. Moreover, in European countries, organic farming is presented as a 'prototype' form of agriculture which may be relevant to assessing and constructing both the practical and cognitive dimensions of sustainable agriculture (Lammerts et al., 1999). Therefore, integrating PPB with organic farming may represent a heuristic way to progress towards sustainability.

This paper is separated into two parts: first, following a brief description of the challenges involved in implementing PPB in European countries, we use an approach combining genetics and sociology to review PPB initiatives in developing countries from the point of view of sustainability. Second, based on previous conclusions, we present and discuss a research-action programme of durum wheat participatory breeding, which is dedicated to organic farming systems currently being used in the south of France.

\section{PPB and agricultural sustainability: outlook in Europe, lessons to be learned from developing countries}

\section{A maxim for new political and scientific projects in European agriculture}

In European countries, PPB is emerging as a political project for farmers' unions and associations who question conventional approaches to plant breeding. This is because they believe these approaches are unable to address the challenge of sustainable agriculture. According to these stakeholders, conventional breeding results in uniformity and genetic stability which conforms with official value for cultivation and use (VCU) regulations. Agricultural sustainability calls for maximizing the adaptative capacities of plants, which, in turn, requires the use of heterogeneous varieties (Kastler, 2007). In the struggle against genetically modified organisms (GMOs) and multinational manufacturers of plant protection products, the notion of PPB also appears as a possible way for these farmers to become independent once again, as well as a way to restore the balance of power between society and markets. Moreover, these farmers object to agronomic research which is still top-down, and based on productivity criteria. This process is deemed to be responsible for sanitary crises such as bovine spongiform encephalopathy (BSE) as well as for the reduction in biodiversity (Joly \& Paradeise, 2003). They no longer trust science and, as citizens, want to play an active role in the definition of research objectives and experimental protocols.

This demand from farmers is supported by geneticists who recognize that conventional breeding methods do not always provide fitting responses to the huge diversity of both environmental conditions and end-users' needs. Furthermore, by focusing on broad adaptability, conventional methods may lead to the loss of genetic resources and biodiversity (Ceccarelli, 1996; Thuillet et al., 2002). A conventional breeding programme can be briefly described as a centralized sequential process in which breeders collect germplasm, evaluate it at controlled experimental stations and make crosses using the best-quality materials. The large quantity of genetic variability that is continuously being created in nature is thus drastically reduced through selection. Finally, surviving lines are distributed to farmers. This process may be effective for farming systems that are sufficiently similar to those in the experimental stations where the research was conducted (Sperling et al., 2001), but it is not suitable for contexts with serious genotype $\times$ environment interactions. These interactions are even more significant when the term 'environment' is considered in its broadest sense, including not only agro-physical but also socio-economic dimensions. Thus, some social scientists also question the ability of institutional plant breeding programmes using conventional methods to ensure agricultural sustainability (Bonneuil \& Thomas, 2004).

Farmers who have appropriated the notion of PPB for European countries refer to the positive impacts of the PPB initiatives developed in 
developing countries. Benefits such as the conservation of biodiversity or the value of farmer's active participation in the research (the valorization of the farmers' role) are highlighted. However, there is huge diversity in PPB programmes implemented in developing countries, in both form and results. Therefore, we have developed an analytical framework which combines genetics and sociology to clarify this diversity, and to assess PPB from the point of view of sustainability.

\section{Combining genetics and sociology to assess sustainability in PPB projects}

Sustainable development addresses three different and interdependent dimensions of the assessment of farming practices: (1) economic viability, (2) ecological preservation and (3) social equity. Such a perspective not only questions the relevancy of techniques, knowledge or indicators for development, it also supposes a new shared attitude to farming. Sustainability is directed towards an unknown future and needs to be considered as a project rather than as an existing state. It is a project for a heterogeneous set of actors and, in agriculture and agro-food sectors, this includes researchers, farmers and other stakeholders, who together have to identify relevant questions and solutions as part of an ongoing process (Röling \& Wagemakers, 1998).

The sociology of innovation, also called 'actornetwork theory', is frequently mobilized to renew research programmes in a 'technical democracy'. Researchers and 'non-experts' such as farmers and traders or consumers meet and discuss research in order to cope with new societal and scientific challenges (Callon et al., 2001). They collectively create a body of knowledge to ensure sustainable development (Aggeri et al., 2006). From this point of view, a PPB programme may be construed as a dynamic, non-linear innovative process. It may be initiated by a leader who has a new idea or project that is put forward with the aim of engaging a set of actors and material objects in a 'socio-technical network'. The question that then needs answering is: 'to what extent do the socio-technical networks, built through PPB programmes actually favour social equity and promote both natural and social diversity, in agreement with the principles of sustainable development?' How do PPB networks preserve and empower the human and natural 'mute entities' (Callon et al., 2001) that are usually left out of, or go unnoticed, in innovation programmes? In practice, how do PPB networks allow the expression of human and natural diversity, thereby enabling people to meet and participate in decision-making processes?

Instead of considering and defending ecological and social criteria separately, genetics and sociology can be usefully combined to assess PPB programmes from the point of view of sustainability. PPB can be interpreted as an innovative socio-technical network, which is likely to enhance both human and natural heterogeneity, to empower mute entities and to facilitate the participation of the different stakeholders concerned. This approach leads us to review PPB initiatives in developing countries from a new perspective, that of their suitability, and not only of their possible practical application in European countries.

\section{Assessing PPB experiments in developing countries from the point of view of sustainability}

'Participatory plant breeding' is a relatively new concept. Nevertheless, a large set of diverse technical, social and organizational strategies for PPB are described in the literature which go beyond the common aim of involving end-users in the breeding process (Morris \& Bellon, 2004). We assessed all of these approaches from a sustainability perspective focusing on their enhancement of natural and social diversity, which is often neglected in comparison to economic viability. Our framework assesses PPB objectives, institutional contexts, forms of interaction between actors, methods and locations of selection. These are the categories usually addressed in PPB programmes (Sperling et al., 2001), in relation to both social and ecological criteria associated with enhancing natural and social diversity.

\section{The objectives of PPB}

PPB refers to two types of approaches: functional and processual (Thro \& Spillane, 2000). Functional approaches aim to obtain better adapted crop varieties, that are more closely tailored to farmers' needs or to those of a supply chain, whereas processual approaches aim to empower 
farmers by developing their skills as plant breeders. These general objectives are now discussed from a sustainable perspective:

Increasing the effectiveness and the efficiency of a breeding programme This objective is commonly mentioned in the literature, and is associated with expressions like 'speeding up the transfer of cultivars and their adoption', 'obtaining adapted plant material', 'increasing the dissemination of cultivars'. PPB is supposed to take into account the farmers' quality requirements and the specificity of their local environments in order to target a wider circle of potential users (Witcombe et al., 2003). However, in practice PPB involves a participatory varietal selection in which cultivars have already been created by breeders and thus, only represents an opportunity to speed up their adoption by farmers. Clarifying whether farmers are involved in the breeding objectives and methodologies or whether they are simply selecting from a breeder's existing cultivars allows us to judge whether farmers are considered simply as consumers or as partners. The role as consumers of bred varieties would seem to be inappropriate in the goal of sustainability.

Improving local adaptation and promoting genetic diversity Local adaptation helps to limit genetic erosion and consequently avoid major risks due to varietal homogeneity at the territorial scale (Ceccarelli, 1996). However in some PPB programmes local adaptation is driven exclusively by agro-ecological criteria, neglecting the essential contribution of human preferences and practices in the conservation of biodiversity and evolution, and thereby reducing farmers to being mere end-users.

Empowering farmers and farmers' organizations PPB can also empower farmers, that is promote their autonomy from multinational seed companies or increase their freedom to choose varieties. It can enable rural communities to maintain the genetic resources they value and to take part in the development of new varieties that suit their needs (McGuire et al., 1999). But many PPB programmes are apparently still driven by diffusionist conceptions of development, in which local societies are supposed to adopt and disseminate the exogenous innovations produced by scientific research (Hocdé et al., 2001).

\section{Institutional context and forms of interaction between stakeholders}

Social diversity and equity are central to the notion of sustainable agriculture and this is expressed in very different ways in PPB. A 'formal' PPB programme is one that is initiated by researchers who invite farmers to take part in the breeding research; a 'farmer-led' PPB programme is one in which farmers construct their own systems of breeding and are responsible for varietal selection, and the multiplication and dissemination of seeds. They may also invite scientists to collaborate and support them. Based on the work of Franzel et al. (2001), a more elaborate differentiation can be proposed whereby leaders of each task (breeding process design, management, etc.) are identified. This sometimes reveals that the concentration of strategic tasks are in the hands of a limited number of specific actors.

Partnerships between farmers and researchers can be thought of as points along a continuum, representing different degrees of interaction. Three kinds of partnerships can usually be distinguished: (1) consultative (information sharing), (2) collaborative (task sharing) and (3) collegial (sharing of responsibility, decision-making and accountability) (Sperling et al., 2001). In practice, partnerships usually appear to be limited to 'participation by assimilation' (Friedberg, 1988) on the part of farmers. They express their point of view without having any effect on decisionmaking, for the sole reason that they are representative of a category or a market (e.g. 'small producers', 'women'). Moreover, the farmers involved are often people with a high socioeconomic status who are already close to the loci of decision-making in a breeding programme. In this case, there is a risk that PPB will strengthen the power of a cluster of already influential people. It may also potentially reflect the point of view of individuals who, in reality, are not representative of all of the stakeholders really concerned. More precisely, the selection of participating farmers with respect to the different stages, methods and locations of a PPB programme reveals the extent to which farmers' participation gives them a decisive influence over the results. 


\section{Stages, methods and location of plant breeding}

A plant breeding project can be split up into five stages: (1) setting breeding objectives, (2) generating genetic variability (from collections or farmers' fields and/or through crossing), (3) selection of variable materials, (4) evaluating experimental varieties, and (5) multiplying and disseminating seeds. These stages are frequently presented in a linear way and very little information can be found about the benefits of managing them in a cyclic way with continuous feedback (Kunz \& Karutz, 1991).

In many so-called PPB initiatives, farmers' participation is limited to the final steps involving evaluation and selecting a few nearly-finished or advanced varieties just before their official release. This is known as participatory varietal selection (PVS). PPB normally entails participatory selection with unfinished or segregating materials, that is with a high degree of genetic variability (Witcombe et al., 1996). However, very few programmes involve farmers in the first three stages of generating variability, setting objectives and selection of unfinished materials. With farmer involvement in these initial stages of plant breeding, many of the varieties used in on-farm trials would have been eliminated earlier if the farmers had been given the opportunity to assess them. Farmers' participation would thus add valuable complementary information to that provided by plant breeders at these early stages (Toomey, 1999).

Farmers' involvement in the breeding process is also closely linked to the vegetal material that is used, valued and shared. Depending on the type (genetic resources, segregating pure lines, populations or advanced material), farmers may be in a position to innovate, adapt or to manage the process dynamically. In addition, if farmers are allowed to handle the materials, this may help them to explain their preferences better when expressing opinions during interviews, in which they face the added pressures of the researcher or the social control of their peers. In PPB, farmers can be given the option to choose one cultivar or to create mixtures (Cleveland and Soleri, 2002). Observation by researchers of farmers' choices can thus produce more interpretable information about relevant substitute varietal structures and ideotypes than direct interviews. However, in practice, farmers' participation is via individual or collective consultation, often due to lack of funding. This is usually within a social context whereby status and identity are at stake, meaning that points of views expressed may be only contingent proposals with no practical relevance (Barbier et al., 2007).

With respect to breeding methods, the most frequent technique used in PPB is mass selection, whereby plants are chosen from the population. This is because it corresponds to farmers' traditional practices and is easy to implement. It allows a large number of plants to be tested and performs well for heritable characters. However, mass selection is not efficient for traits with low heritability, and the risk of loosing variability for such characters is by no means negligible (Gallais, 1990). With that risk in mind, deciding on the methodology based on a social criterion, in this case the valorization of local practices can result in an ecological imbalance. From a sustainability perspective, in which both social and ecological dimensions are at stake, farmers' traditional breeding methods need to be combined with other techniques proposed by researchers, in order to simplify implementation, and ensure efficiency of selection and conservation of biodiversity. Evolutionary-participatory breeding is a good example of this concept which combines two specific breeding methods: evolutionary breeding and PPB (Jones et al., 2005).

PPB can also be characterized by the location of selection: decentralized selection performed in the target environment has been used to emphasize favourable genotype $\times$ environment interactions. It is a powerful tool for adapting plants to physical environments or cropping systems. However, plant breeding based on decentralized selection can fail to achieve its objectives if it does not make use of farmers' knowledge about the plant concerned, its environment and all of its different uses on the farming community scale (Morris \& Bellon, 2004). PPB programmes can also be implemented in centralized research stations where farmers are invited to visit and practice selection of lines grown in experimental conditions. From the point of view of sustainable agriculture, it is useful to combine these two breeding locations in a PPB project. Indeed, the efficiency of the location of selection can be determined by the correlation between the performance of a genotype in this 
location and its results in the targeted sites. It can also be assessed through the statistical precision of measurement of the performance of the genotypes in a given location of selection (heritability in the broadest sense). As centralized PPB aims to maximize heritability, decentralized PPB leads to a higher performance correlation towards specific sites (Atlin et al., 2001).

PPB projects in developing countries are thus very diverse. Combining genetics and sociology to assess them from the point of view of sustainability leads to several conclusions:

- farmers' participation is essential but depending on the way it is construed and organized, may be counterproductive because it can strengthen social inequalities and reduce biodiversity,

- combining functional and processual approaches with farmers' and researchers' points of view, knowledge and practices, would contribute to creating an economic, social and ecological balance.

This framework provided the tools we needed to reply to a request from French farmers concerning organic durum wheat from the perspective of sustainable agriculture.

\section{The participatory organic durum wheat breeding experiment: trajectory and outlook}

\section{From PPB in developing countries to European organic farming}

What we have learnt from PPB experiments in developing countries is of great interest for the implementation of sustainable organic farming in Europe. Indeed, organic farming faces similar constraints to those faced by producers in marginal areas of developing countries: a heterogeneous environment, the wide range of different farmers' needs, and particularly the lack of suitable varieties and the lack of interest on the part of the formal breeding sector. The few PPB projects implemented in European countries are mainly concerned with organic agriculture (Desclaux \& Lançon, 2005). Beyond pragmatic challenges, PPB is said to offer a relevant way of coping with the main principles and objectives of organic agriculture, as defined by the IFOAM, the leading European scientific and professional institution in matters of organic farming. Organic farming aims '(i) to maintain and conserve genetic diversity through attention to onfarm management of genetic resources, (ii) to recognize the importance of, and protect and learn from, indigenous knowledge and traditional farming systems' (IFOAM, 2005). Organic production has to be based on closed production cycles, natural self-regulation and agro-biodiversity promotion. Moreover, according to Lammerts et al. (1999), organic farming also requires specific socio-economic features: close interaction between farmers, marketers, manufacturers and breeders, and regulations that are geared to organic agriculture and to the diversity of farming systems. PPB may cope better with such agro-ecological and socio-economic criteria than conventional approaches.

There are nevertheless huge differences between developing country and European contexts. Thus PPB approaches in developing countries cannot simply be 'transferred' to European countries, especially as they produce nuanced results. In developing countries, PPB is mostly implemented for subsistence farming. The range of different actors involved is small and the participation of farmers and other stakeholders such as manufacturers is limited. In Europe, PPB may concern farmers embedded in more complex supply chains. The participation of all the different stakeholders and a multidisclipinary approach are required to organize both the production and the exploitation of co-bred seeds, by promoting better prediction and management of genotype $\times$ environment interactions. The case of organic durum wheat thus appeared to be a relevant opportunity to take up the challenge.

\section{From initial demand to a research-action project}

The initial request came from organic durum wheat producers in the south of France and manufacturers of organic pasta in 2001. Indeed, durum wheat produced in organic conditions does not meet the quality requirements of the processing industry (notably too low protein content). As a result, more than half the French organic durum wheat harvest is sold for animal feed while pasta manufacturers are obliged to import durum wheat grain for human consumption without guaranteed traceability. The sustainability of the durum wheat supply chain is 
thus in question. Given the lack of interest by private breeding firms, a number of farmers turned to public researchers working on the diversity of cereal genetic resources at the National Institute of Agronomic Research (INRA). Some of these farmers only wanted to obtain cultivars adapted to their organic growing conditions. Others were looking for genetic resources to produce their own seeds, thus embedding their demand in a more political issue of farmers' rights.

Geneticists called on social scientists and agronomists to make a joint diagnosis in the two main French regions concerned with the production of organic durum wheat: the Camargue and the Pays Cathare. These territories differ with respect to soil salinity, crop rotation and the extent of animal rearing. Initial investigations confirmed the absence of varieties adapted to the limiting nitrogen conditions that characterize the organic systems of these regions. Indeed, all available durum wheat cultivars come from breeding programmes implemented within conventional growing systems, without nitrogen limitation. Developing a breeding process in organic conditions thus appeared to be relevant, but the question was how to organize the participation of the different stakeholders with a view to ensuring sustainable production. Moreover, the case of organic durum wheat posed very strategic questions: how to reconcile the different needs of organic producers and pasta manufacturers? How to tackle genotype-environment interactions considering the environment in its broadest context? How to take into account the farmers' request to play an active role in the plant breeding chain, which historically has been under the control of state institutions or private firms? As a geneticist and a sociologist, we thus proposed a multidisciplinary action-research programme constructed around thematic activities.

\section{Dynamics of the organic durum wheat socio-technical network: from breeding to sustainable development}

\section{Participatory setting of objectives, evaluation and initial feedback}

To identify the needs of end-users and the different constraints faced by the farmers, representatives of the whole organic durum wheat supply chain were involved in the first stage of the project, that is the setting of objectives and of selection criteria. Each stakeholder, from farmers to consumers, was invited to formulate their ideotype as well as their reasons to produce, buy or eat organic durum wheat and the results they expected. Collaboration between a geneticist and a sociologist resulted in the identification of a wider range of needs and in a broader understanding of the requirements of all the professional partners. For example, the sociologist helped identify and score some subjective features such as taste, aroma, appearance or texture, which are rarely taken into account by breeders.

At the same time, a wide survey including questions about farmers' cropping systems, varietal preferences and economic outlets, was conducted to identify the practices and points of view of a large number of organic farmers in the two regions concerned. The distribution of the questionnaires was facilitated by regional farmers' organizations. The needs differed greatly between the two regions. In the Camargue, bull and sheep rearing means natural nitrogen is available for wheat during the vegetative period, though not during the period of elaboration of seed quality. Farmers consequently need varieties that can efficiently mobilize the nitrogen stored in their vegetative parts, and are tall enough to feed the animals. In the Pays Cathare, nitrogen is a limiting factor even during the vegetative period and weed infestation is consistently high. The farmers therefore require a variety with a welldeveloped root system which is able to compete with weeds and to uptake nutrients efficiently and early. Conventional breeding has never focused on these particular traits and some varieties have even been 'counter-bred' (stem height for example).

Beyond the differences between the regions, the data collected from the individual survey (face-toface interviews and questionnaires) of a representative sample of producers led to the identification of two contrasting farmer's attitudes to durum wheat varieties. This depended on their different uses, objectives and networks: (1) pioneers who were motivated for ethical reasons and who changed to organic farming a long time ago, who favoured a high diversity of species in their crop rotations and whose farming practices were stable; these farmers belonged to ecological networks and were sometimes involved in political movements 
concerned with GMOs; (2) the newly converted, whose recent conversion may be seen as a strategy to overcome difficulties encountered in the formal farming sector, who chose mixed cropping systems (organic and conventional) to limit risks related to a technical and/or economic failure in the organic production system. Their cropping systems were not stable, their crop rotations were limited and their cropping practices, though they respect organic specifications, are actually based on conventional practices. Their relationships have mostly developed with the technical advisers who represented the manufacturers of plant protection products.

In parallel, the results of enquiries with a contrasted sample of pasta and semolina manufacturers (big firms, family firms dedicated to organic food and markets) highlighted the wide range of buying criteria and strategies, especially with respect to organic products. This led farmers and also geneticists to a heterogeneous perception of 'downstream actors'. They identified not only one, but several ideotypes, which were adapted to different situations and objectives after linking upstream preferences with downstream requirements.

This was an ongoing process, so the setting of objectives was not completed after the first set of meetings, enquiries and observations. An additional step - the evaluation of lines - was implemented right at the beginning of the project and provided precious feedback for the definition of farmers' preferences as well as a description of the conditions in which the cultivars would be used (see Figure 1). Evaluation began with quasifixed varieties developed by public research. This evaluation, which took place over several different periods, mobilized different actors. Regular field visits were organized especially during flowering and at physiological maturity. This provided the opportunity for farmers, manufacturers and researchers to discuss genetic diversity in concrete terms around experimental plots (on the farm or in research stations). Cultivars were considered as 'intermediary objects' (Vinck, 1988:80) in the socio-technical network, facilitating the exchange of knowledge and points of view about 'the culti$\operatorname{var}(\mathrm{s})$ that suit(s) me best'. All the actors were invited to express their point of view and also to enter scores in a grid. The geneticist and sociologist

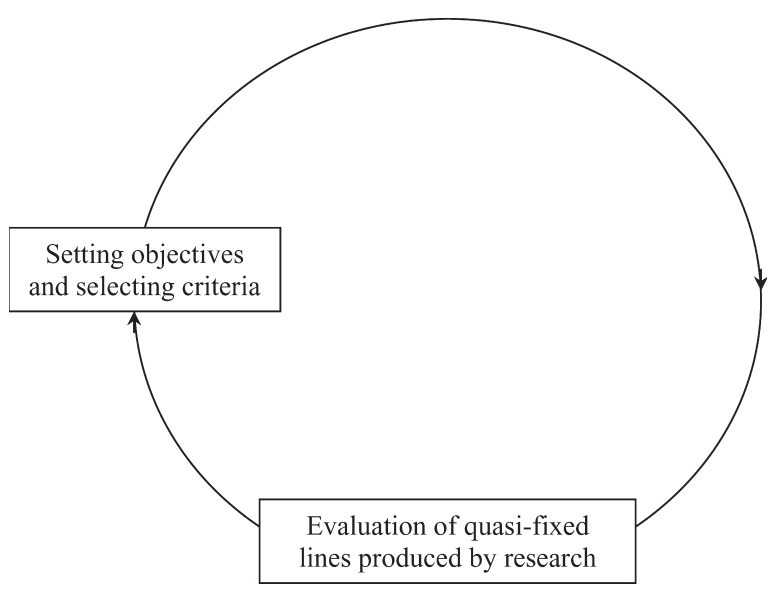

Figure 1 Steps in which farmers participate in the first stage of the organic durum wheat breeding project (2001-2005)

collaborated in order to allow the widest possible 'critical participation' (rather than 'participation by assimilation'; Friedberg, 1988: 80). This helped the farmers' to score cultivars by providing genetic data or by adapting the scoring system to include specific terms of local farmers. Small subgroups based on mutual affinity were also created in order to facilitate free expression. Whilst the sociologist was able to evaluate what the speaker was saying based on their social position, the geneticist provided tools to help people explain their criteria as well as the correlations they observed between them. Post-harvest evaluations were also made based on agronomical and technological results provided both by researchers and pasta manufacturers. The results were discussed by all the actors and this synthesis provided a further opportunity for manufacturers, distributers, farmers and researchers to decide jointly which lines to keep or to use as genitor. Finally, this form of evaluation, called participatory varietal selection (PVS), led to the re-examination of the initial breeding objectives. It helped to identify both parents and important target traits, such as the capacity to produce at ultra-low density.

The first stage of the project - which corresponded to the emergence of a socio-technical network around the innovation of organic seeds included moments of tension and conflict, which were perceived as disruptive but also as learning opportunities (Callon et al., 2001); these occurred 
particularly with respect to the most suitable cultivar structure for organic farming, as discussed at IFOAM meetings: pure line or population? At this stage, public researchers played the role of experts assessing both the technical and socioeconomical feasibility of specific ideotypes. But above all, they functioned as mediators between the diverse actors and varying points of view (Chiffoleau et al., 2001), especially between upstream and downstream actors, who were not used to meeting each other and were not particularly motivated to do so. Our aim was to let everyone involved in the project know that everyone else had 'good reasons' for their opinions, by taking into account the opinions of a whole range of different actors, not only those of the 'leaders' which unfortunately is often the case. In particular, the sociologist enlarged the sample to include 'mute entities', such as shy people who risked being 'overpowered' by militants. Our PPB programme thus underwent changes during the whole course of the production and selection of different generations of cultivars, generating learning processes and mutual trust. However, as already revealed by innovation sociologists, the socio-technical network around durum wheat also represents a power issue for 'manipulators', who try to choose 'big talkers' as apparently legitimate representatives of actors concerned by the project and to exclude the others. This led us to consistently defend the interests of all the actors and of the different objectives from the point of view of sustainability, and also to diversify and strengthen different 'roles' within the network in order to enhance the value of each individual participant (Callon et al., 2001).

\section{Five years later: PPB project evolution and outlook}

After a relatively short time, some actors asked to participate more in the PPB programme. They not only wanted to take part in the evaluation of fixed lines, but also in the other preliminary steps (see Figure 2). Initially, the advantage of involving other stakeholders in generating variability was not clear for researchers. This step, which is generally performed by breeders, implies collecting, characterizing, and evaluating the use of adequate genetic diversity. Despite this precedent, we decided to evaluate wild species on the farms.

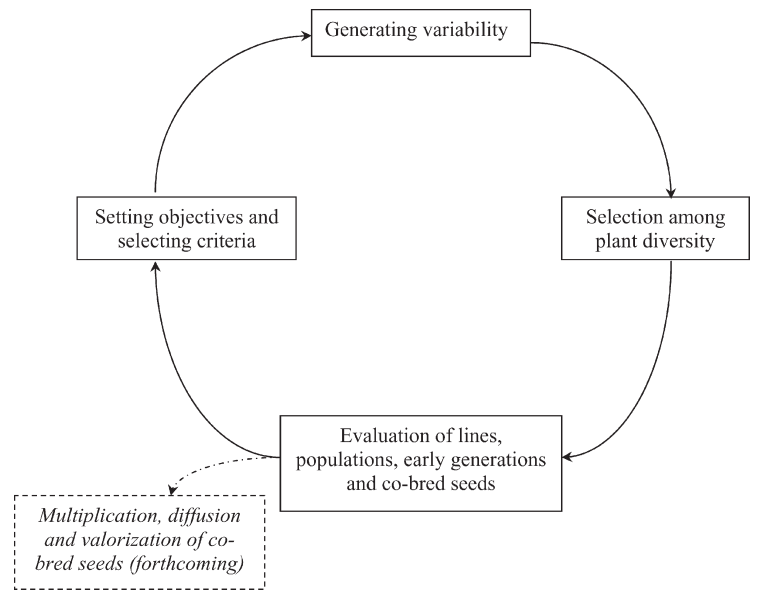

Figure 2 Steps in which farmers participate in the current stage of the organic durum wheat project

A joint choice of parents was thus made from wild species and genetic resources preserved at INRA, and evaluated both at the research station (ex situ) and on the farm (in situ). In situ evaluation of genetic resources aimed both to increase farmers' and other actors' awareness of biodiversity and to open up new perspectives about suitable ideotypes. However, public researchers performed the manual crosses to create new broad base populations.

Management of these populations was dynamic and participatory, as a network of seven voluntary farmers were in charge of biodiversity maintenance in contrasting environments. Biodiversity maintenance is accomplished not by allowing population drift at the risk of losing favourable alleles, but by applying a low selection pressure to correct competitive effects. The challenge is not only to maintain diversity but also to manage it, which supposes that the biology of cultivated species is well known. The farmers themselves asked for training in these subjects, even when they were not involved in the experimental network. Workshops were thus organized at regular intervals to improve the farmers' knowledge of genetics and to facilitate critical participation. The farmers' considerable expertise and capacity for observation was acknowledged by all the stakeholders involved and the complementarity of knowledge and knowhow enabled dynamic in situ conservation of genetic resources.

The specific farmers' knowledge was also mobilized for the joint selection of genetic 
resources. Farmers selected the material they judged to be the best suited to their constraints and particular environment. However, it was during this process that the socio-technical controversy about the most relevant varietal structures increased and reached a peak with respect to the best breeding method (recurrent or pedigree method). We tried to elucidate the debate through discussions about the question with our different partners. In reproducible environments, researchers use privileged stable structures such as pure lines. But as mentioned by our partners, this type of environment is rare in the context of organic agriculture and most organic farmers require heterogeneous structures. Heterogeneity is indeed synonymous with homeostasis, that is steady behaviour, and enables adaptation of the cultivar to diverse environments (Wolfe, 1992). The project geneticist argued that heterogeneous cultivars are less productive than the best components (Gallais, 1990). Pure lines may also be of great interest in certain situations, even though some farmers rejected them right away because they considered them to be intrinsically linked with multinational firms and GMOs. The different partners thus agreed to keep diverse kinds of varietal structures. Open discussion led to the choice of the recurrent method as the most relevant breeding method for the maintenance of biodiversity and the one most consistent with the partners' values. As shown by Gallais (1990), the recurrent method of breeding contributes both to improving the pool genetic resources and to creating suitable new materials.

Up until 2005, some farmers had been given very early generations $(\mathrm{F} 1-\mathrm{F} 2)$ to help scientists to better identify genotype $\times$ environment interactions and to analyse the specific capacity of adaptation of the plant materials. This also confirmed that giving farmers the opportunity to confront genetic diversity helped us to identify their varietal preferences more efficiently than with a survey. Being able to handle materials freely in the real context in which they would be using them enabled farmers to talk about other criteria than those that had been brought to light in the first stage of the programme, for instance competition with weeds and maturity.

Thanks to the farmers' critical participation, the step concerned with disseminating varieties is evolving in a very different way from a conventional, centralized breeding programme. The adoption of cultivars will very likely be facilitated when farmers are involved as decision-makers in their elaboration. However, the question of property rights to co-bred materials is an urgent issue which now requires legal assistance. In general, the challenge is now to move on from socio-technical networks in which diverse materials are created, to 'organized action systems' (Friedberg, 1988: 24) allowing the legal production and the economic exploitation of co-bred cultivars. Involving manufacturers from the start of the project facilitates this transition but crucial issues about the way to organize and control 'fair' partnerships nevertheless have to be faced. With this aim in view, the PPB programme needs to draw on lessons issued from fair trade and ethical sourcing initiatives (Chiffoleau et al., 2007). In practice, two kinds of 'ethical' organized action systems are in progress: the first, 'the semi-industrial process', tends to bring producers and quite big firms together around lines and may be framed by written contracts and technical guidelines. The second, more consistent with a 'small farmers' outlook, tends to attract small producers, family firms and 'engaged consumers' around populations or mixes that may be valued through diverse organic foods made from durum wheat and short food supply chains.

\section{Conclusion}

Based on the critical review of PPB initiatives implemented in developing countries, which are often 'overestimated' by European farmers, we tried to design and implement a PPB project. Using organic durum wheat as an example, we developed a socio-technical network which may be relevant in European conditions in the face of sustainability challenges. Our ongoing project network combines three different objectives: (1) to obtain suitable planting material by improving local adaptation, (2) to promote genetic diversity, and (3) to valorize farmers' knowledge and know-how. It is neither a farmer-led nor a formal-led programme, but a programme led by both professionals and researchers, in which farmers' critical participation is encouraged right from the first steps of the breeding scheme. The 
main decisions have been taken collectively to cope with the sustainability challenges addressed by organic agriculture. This represents a major breakthrough from conventional breeding schemes, insofar as farmers play the role of real partners and not only of consumers or end-users of newly created varieties.

This programme's experience also highlights the benefits obtained from open interactions between different professional partners and researchers from relevant disciplines. Involving pasta manufacturers in the programme allowed farmers to leave behind their original notion of manufacturers as multinational profit-makers with no societal preoccupations, and to identify concrete options for collaboration. The story of the project also reveals the complementarity of genetics and sociology in dealing with both the technical and social challenges linked with PPB transfer to European countries. This next step involves more in-depth collaboration with agronomists, economists and legal experts to better formalize and implement different but complementary action systems around specific varieties, combining technical innovation with specific rules. However, there is not only one way to organize breeding, farming and valorization systems with a view to sustainability. Agricultural projects that promote multi-actor participation right from the beginning, that is right from the plant breeding stage, along with an ethical perspective that takes in account actors or material objects that are usually discredited, may be a more fitting response to sustainability challenges. Co-breeding is no longer only an end in itself but also a means of facilitating the production of knowledge and rules relevant for the development of circumscribed and meaningful agro-food systems, rather than merely the adaptation of models produced in other settings.

\section{References}

Aggeri, F. and Hatchuel, A. (2003) Ordres socioéconomiques et polarisation de la recherche en agriculture. Pour une critique des rapports science-société. Sociologie du Travail 45 (1), 113-133.

Aggeri, F., Pezet E., Acquier A. and Abrassart A. (2006) Organizing Corporate Sustainability: Pioneer Corporate Strategies and Institution-Building. London: Edward Elgar.
Almekinders, C.J. and Elings, A. (2001) Collaboration of farmers and breeders: Participatory crop improvement in perspective. Euphytica 122, 425-438.

Atlin, G.N., Cooper, M. and Bjornstad, A. (2001) A comparison of formal and participatory breeding approaches using selection theory. Euphytica 122, 463-475.

Barbier, J.M., Chiffoleau, Y. and Desclaux, D. (2007) Un dispositif pluridisciplinaire et participatif pour l'innovation variétale: Perspectives à partir de diagnostics d'agronomes. In P. Prévost (ed.) Agronomes et innovations, Les entretiens du Pradel 2004. Dijon: Educagri (forthcoming).

Bonneuil, C. and Thomas, F. (2004) Du maïs hybride aux OGM : un demi-siècle de génétique et d'amélioration des plantes à l'INRA. In P. Boistard, C. Sabbagh et I. Savini (dir.) Actes du colloque : l'amélioration des plantes, continuitès et ruptures, 17-18 Oct. 2002, Paris, INRA Editions, 42-53.

Callon, M., Lascoumes, P. and Barthes, Y. (2001) Agir dans un Monde Incertain. Essai sur la Démocratie Technique. Paris: Seuil.

Ceccarelli, S. (1996) Positive interpretation of GxE interactions in relation to sustainability and biodiversity. In M. Cooper and G.L. Hammers (eds) Plant Adaptation and Crop Improvement (pp. 467-486). Wallingford: CABI.

Chiffoleau, Y., Dreyfus, F. and Touzard, J.M. (2001) Chercheurs et viticulteurs partenaires pour l'innovation: interactions, institutions et apprentissages. Natures, Sciences et Sociétés 3, 29-36.

Chiffoleau, Y., Dreyfus, F. and Touzard J.M. (2007). Fair trade and ethical projects: New challenges for wine co-operatives? In R. Chaves, J.L. Monzon and R. Spear (eds) The Future of Cooperatives in a Growing Europe, Valencia. IUDESCOOP/Valencia University (forthcoming).

Cleveland, D.A. and Soleri, D. (2002) Farmers, Scientists and Plant Breeding: Interacting Knowledge and Practice. Oxford, UK: CAB International.

Desclaux, D. and Lançon, J. (2005) Sélection participative. On WWW at URL http://selection-participative. cirad.fr (accessed 2005).

Franzel, S.R., Coe, R., Cooper, F., Place F. and Scherr, S.J. (2001) Assessing the adoption potential of agroforestry practices in sub-Saharan Africa. Agricultural System 69, 37-62.

Friedberg, E. (1988). L'analyse sociologique des organisations. Paris, L'Harmattan.

Gallais, A. (1990) Théorie de la Sélection en Amélioration des Plantes. Paris: Masson.

Godard, O. and Hubert, B. (2002) Le Développement Durable et la Recherche Scientifique à l'INRA. Research Report. Paris: INRA.

Hocdé, H., Lançon, J. and Trouche, G. (eds) (2001) La sélection participative: Impliquer les utilisateurs dans l'amélioration des plantes. Proceedings of the Sélection Participative Workshop. CIRAD, Montpellier, September 5-6, 2001. 
IFOAM (2005) Uniting the organic world. On WWW at www.ifoam.org (accessed 2005).

Joly, P.B. and Paradeise, C. (2003) Agriculture et alimentation: nouveaux problèmes, nouvelles questions. Sociologie du Travail 45 (1), 1-8.

Jones, S.S, Murphy, K., Lammer, D., Lyon, S. and Carter, B. (2005) Breeding for organic and low-input farming systems: An evolutionary-participatory breeding method for inbred cereal grains. Renewable Agriculture and Food Systems 20 (1), 48-55.

Kastler, G. (2007) Sélection participative, à la jonction entre sélection paysanne et amélioration des plantes. Le Courrier de l'Environnement de l'INRA, Special Issue (forthcoming).

Kunz, P. and Karutz, C. (1991) Pflanzenzuchtung Dynamisch. Die zuchtung standortangepasster Weizen und Dinkelsorten. Research Report. Goetheanum, Dornach.

Lammerts van Bueren, E.T., Hulscher, M., Haring, M., Jongerden, J., van Mansvelt, J.D., den Nijs, A.P.M. and Ruivenkamp, G.T.P. (1999) Sustainable Organic Plant Breeding. A Vision, Choices, Consequences and Steps. Driebergen: Louis Bolk Instituut.

McGuire, S., Manicad, G. and Sperling, L. (1999) Technical and Institutional Issues in Participatory Plant Breeding Done from a Perspective of Farmer Plant Breeding. Working Document 2, PRGA, CGIAR.

Morris, M.L. and Bellon, M.R. (2004) Participatory plant breeding research: opportunities and challenges for the international crop improvement system. Euphytica 136, 21-35.

Röling, N.G. and Wagemakers, M.A. (eds) (1998) Facilitating Sustainable Agriculture: Participatory Learning and Adaptative Management in Times of
Environmental Uncertainty, Cambridge: Cambridge University Press.

Sperling, L., Ashby, J.A., Smith, M.E., Weltzien, E. and McGuire, S. (2001) A framework for analyzing participatory plant breeding approaches and results. Euphytica 122, 439-450.

Thuillet, A.C., Bru, D. and David, J. (2002). Direct estimation of mutation rate for 10 microsatellite loci in durum wheat, Tirticum turgidum (L) Thell. ssp durum desf. Molecular Biology and Evolution 19, $122-125$.

Thro, A.M. and Spillane, C. (2000) BiotechnologyAssisted Participatory Plant Breeding: Complement or Contradiction? Working Document 4, CGIAR.

Toomey, G. (1999) Farmers as Researchers: The Rise of Participatory Plant Breeding. IDRC Project, number 950019. On WWW at http://www.idrc.ca/ en/ev-5559-201-1-DO_TOPIC.html.

Vinck, D. (1999) Les objets intermédiaires dans les réseaux de coopération scientifique. Contribution à la prise en compte des objets dans les dynamiques sociales. Revue Française de Sociologie XL (2), 385-414.

Witcombe, J.R., Joshi, A., Joshi, K.D. and Sthapit, B.R. (1996) Farmer participatory crop improvement I: Varietal selection and breeding methods and their impact on biodiversity. Experimental Agriculture 32, 445-460.

Witcombe, J.R., Joshi, A. and Goyal, S.N. (2003) Participatory plant breeding in maize: A case study from Gujurat, India. Euphytica 130, 413-422.

Wolfe, M. (1992) Barley diseases: Maintaining the value of our varieties. In L. Munck (ed.) Barley Genetics, Vol. VI (pp. 1055-1067). Copenhagen: Munksgaard International. 